\title{
DECIDIENDO ÉTICAMENTE CON EL CORONAVIRUS
}

\author{
Sergio Rodero \\ Profesor doctor. Universidad de Salamanca \\ Especialista en Educación para la Ciudadanía \\ E-mail: srodero@usal.es
}

Convidado

Dirigir la especie humana es tarea ardua, ingobernable. Ésta es la misión de los Gobiernos de turno para con sus ciudadanos y sus vidas. Pero todos viajamos en el mismo navío, no nos olvidemos, todos podemos salvarnos o morir, es el COVID-19: un Titanic que nos ha llegado de improviso y desprovistos. Un problema mundial en nuestra aldea global, que exige una respuesta y solución común, si todos queremos superarlo pronto y minimizar sus consecuencias.

Los mandatarios y poderosos pueden escoger en sus respectivas poltronas resolverlo atendiendo a sus intereses partidistas y políticos o decidir éticamente en momentos del coronavirus, y el tiempo apremia.

Ética (del griego ethos, costumbre, hábito, carácter) significa principalmente acción, y toda acción implica una elección y decisión. Todos sabemos definir lo bueno y lo malo. Ahora bien, no hablamos de una sola ética o elección/decisión, hay muchas éticas, puesto que hay muchas formas o maneras de ser, de ser bueno o malo. No podemos quedarnos con la costumbre (mos/moris, para los latinos), porque la Ética es mucho más. Los filósofos bien sabemos que es una teoría de la vida, con sus diferentes tipos: frónesis, prudencia; areté; y eunoia.

¿Relativismo o universalismo moral? Hoy ya estamos en un pluralismo moral, con unos mínimos morales compartidos. La ética choca con el valor universal en algunas creencias, culturas, sociedades y hace muy difícil su universalización y respeto a los derechos más básicos del ser humano, los Derechos Humanos y la dignidad de la persona. Claro que hay conceptos morales que son absolutamente universales y no subjetivos.

La Humanidad ha evolucionado mucho en multitud de aspectos y mucho también éticamente, desde el relativismo y subjetivismo moral hasta el universalismo y pluralismo moral de hoy. Hemos superado la moral primitiva, la época de las grandes civilizaciones, la primera Modernidad, hasta llegar a los siglos XVI y XVII y hablar de la tolerancia. Las ideas de John Locke, de Voltaire y de otros pensadores de la época exigen la tolerancia desde posicionamientos religiosos, mas emplean cada vez más argumentos que son aceptables por creyentes y no creyentes: aquí radica el germen del pluralismo moral.

El pluralismo moral es un equilibrio entre dos extremos, dos posibilidades, que son totalmente antagónicas entre sí: monismo moral y politeísmo moral. Ante un mismo código moral único o un "politeísmo axiológico" que llama el filósofo social Max Weber, encontramos equilibradamente el pluralismo moral. Éste mantiene que es posible una fórmula intermedia o harmónica: unos cuantos valores básicos compartidos sirven de encuadramiento para que las personas y los grupos o comunidades mantengan distintas creencias morales no compartidas.

Esta pandemia vírica es global, como lo son nuestras sociedades y nuestra vida hoy. Habitamos sociedades moralmente pluralistas, en donde convivimos personas que poseemos 
distintas concepciones morales de lo que es una vida buena, diferentes modos de concebir el mundo o cosmovisiones, distintas maneras de entender al hombre y la historia. La convivencia se da porque compartimos al menos unos valores básicos de justicia.

Venimos escuchando hasta la saciedad crisis económica, ahora crisis sanitaria, muchas crisis nos afectan y poco o nada se habla de la gran crisis de valores del ser que somos. Jamás estuvimos tan comunicados como hoy y nunca fuimos tan fracasados en comunión de seres como actualmente. ¿Tuvo que llegar esta pandemia global para darnos cuenta?

¿qué se está haciendo mal? ¿hacia dónde crecemos? ¿adónde queremos ir? ¿o mejor aún, adónde nos llevan?

Los mínimos de justicia son el conjunto de valores básicos que comparten todas, o casi todas, las concepciones morales de una sociedad pluralista. Hablamos, por ende, de valores que se pueden exigir a todos, ya que son la base de una convivencia justa y pacífica. Igualmente, tenemos unos máximos de felicidad, que son las propuestas que ofrecen las distintas concepciones morales. Es absolutamente lícito convidar a los demás a compartir esos valores y creencias, pero tratar de imponerlos sería una expresión de intolerancia contraria al pluralismo moral.

Como nos recuerda Jürgen Habermas, las sociedades no sólo aprenden técnicamente, sino también moralmente. Por eso, para juzgar si una norma es justa, intenta ponerse en el lugar de cualquier otro. Esto ha acontecido con las sociedades occidentales, como la nuestra, que, en efecto, cuando hablan sobre lo que es justo e injusto, consideran justas esas normas que favorecen a todos los afectados por ellas aunque después las infrinjan habitualmente. Con lo cual existen unos mínimos de justicia con respecto a los que ninguna sociedad desea retroceder, al menos literalmente. Esos valores fundamentales conforman lo que se llama la ética cívica.

No vale todo en el pluralismo moral. Algunos valores pueden servir como marco de convivencia pacífica y justa entre seres humanos, mientras que otros no sólo no sirven, sino que pueden ser un obstáculo para esa convivencia. Hay unos valores éticos mínimos en los que coinciden todos los credos o religiones y aquellas personas que manifiesten no creer en ninguno. Resumidamente pasan por ser éstos: la libertad, entendida como autonomía moral y política; la igualdad (no dominación, igualdad de bienes, igualdad material, social y cultural, igualdad de oportunidades, de autoestima también); la solidaridad; la tolerancia o el respeto activo; y una actitud dialógica.

Parecería convenir todos, baste de prueba, si recordáramos las palabras del propio Confucio, no hagas a los demás lo que no te gustaría que te hicieran a ti; o el mismo Jesucristo transformó este pensamiento en positivo al decir: haz a los demás lo que te gustaría que te hicieran a ti. Estamos asistiendo estas semanas a estas reflexiones y decisiones en términos médicos y en momentos tan críticos como vivimos, con miles de muertes y miles y miles de contagios.

Somos sociedades pluralistas y exigimos moralmente unos mínimos y respetamos activamente unos máximos. Los valores "máximos" son los ideales de vida buena, los proyectos de felicidad que ofrecen las distintas concepciones religiosas y filosóficas, o sea, los distintos modos de concebir al ser humano, su historia y su posible realización plena. Nos hemos ido haciendo históricamente en convivencia, forjando una ética cívica en lo que John Rawls denomina un "consenso entrecruzado". Es esencial, pues, potenciar esos mínimos que ya unen a todos y posibilitan construir un mundo juntos y respetar activamente las premisas que dan vida a cada concepción.

La ética es absolutamente crucial para nuestras vidas y profesiones, para nuestro hacer y nuestras decisiones. Lo vemos muy bien en decisiones históricas y grandes acontecimientos del pasado, y lo tenemos que ver ahora en esta crisis sanitaria mundial. Más que nunca, un buen criterio ético es fundamental en estos momentos. Nos permite resolver muchos dilemas que se producen a diario en tiempos de coronavirus. La vida es una constante elección y elegir bien no es fácil.

Estas semanas se habla mucho de elegir vidas en momentos críticos y con tantas vidas peligrando ante el poder del maldito COVID-19. Un dilema ético, correctamente planteado, debe 
ser resuelto éticamente, no inteligentemente. La mayoría de los dilemas presentan conflictos entre normas legales y valores morales o entre valores morales de distinta importancia o jerarquía. La muestra de sujetos a los que se les presenta el dilema debe colocarse imaginariamente en el lugar del protagonista, elegir la alternativa que considera más correcta y justificarla mediante un razonamiento moral. Después de Kohlberg, el método de los dilemas se ha venido empleando tanto en la investigación clínica o médica como en la educación en valores morales.

Toda vida es digna de ser vivida, toda vida ha de ser respetada, al modo kantiano. Lo más ético, sin duda alguna, es salvar vidas. Cuando no se pueden salvar todas, ¿cómo decides? Los sanitarios y profesionales de la salud en las Unidades de Cuidados Intensivos se están dejando la piel y el alma en recomponer vidas para no tener que elegir y sopesar, ante un dilema. Y es que, sobre todo, un dilema ético lo que tiene que tener en cuenta es que ha de ser resuelto atendiendo a la escala de magnitudes de sus alternativas en juego.

Arribó un virus a España a finales de enero, presuntamente proveniente de China, y de un caso hay a día de hoy más de cien mil personas infectadas y más de diez mil fallecidos. Cabe plantearse el dilema grande en términos éticos: ¿Vale más la economía que la vida humana? Esto ha sido muy evidente en el caso británico, en donde a decisión del Primer Ministro Boris Johnson, se han retrasado las medidas de confinamiento poblacional por valorar más la condición económica del país que la salud de los ciudadanos en situación de más vulnerabilidad. Esto es una barbaridad ética, pero también supondría una catástrofe a otros niveles.

No sólo nos referimos al caso inglés, ya fuera de la Unión Europea por cierto, también se habla y mucho estos días de si el retraso en la toma de decisiones de nuestros gobiernos del sur de Europa no haya seguido los mismos criterios y patrones, al menos indirectamente: para no resentir la economía, pues algunos expertos fiscales ya aseguran que esta pandemia mundial traerá consigo una consiguiente crisis financiero-bursátil superior a la vivida en 2008.

El coronavirus ha sometido al mundo a una crisis sanitaria que marcará una época y un año, 2020. Tras estallar en el gigante asiático en 2019, el ya famoso COVID-19 ha logrado propagarse desde inicios de este año por todos los continentes, aunque se ha cebado especialmente con el Viejo Continente y EE.UU., convertidos ya en el punto rojo de los contagios. Tras amedrentar a los chinos, Italia fue la nación europea que recibió el testigo y mayor embestida de casos contagiados, aunque éstos se han multiplicado exponencialmente en nuestro país en las últimas semanas hasta el punto de haberse prolongado el Estado de Alarma decretado por el Gobierno de España y nuestra Constitución.

Esperanzados estamos con frenar el número de contagios y romper la curva, hacer que descienda y ver una salida del túnel, que la habrá. Intentemos entre todos juntos contener esta guerra, pareciera una guerra biológica, una película de ciencia ficción demasiado real. Desde luego, en España asistimos a un desastre humano, una gripe muy letal, como letal será para nuestra inestable economía.

Yo me quedo con Leibniz, el último genio universal, aunando Teoría y Práctica (Theoria cum Praxi era su lema). Nunca se puede separar la teoría de la práctica, no debiera. La teoría nos ayuda a fijar criterios ahora y siempre en medio de una casuística, cuando hay que decidir y optar rápidamente y cuando los intereses implicados pueden ser de ingente alcance y envergadura.

Espero haber reflexionado algo y hacerles pensar en la situación dramática pero vital, como diría Leibniz, que nos trae nuestro enemigo coronavirus. Que nuestros dirigentes políticos se guíen por el criterio ético, independientemente de los efectos que de ello se deriven. La ética y la moral nunca fallan, apuesta segura.

Aprendamos la moraleja para no volver a repetir errores, hagamos de COVID-19 un COVIDA-20. 